\title{
The sesquiterpene lactone eupatolide sensitizes breast cancer cells to TRAIL through down-regulation of c-FLIP expression
}

\author{
JONGKYU LEE ${ }^{1}$, CHEOL HWANGBO $^{1}$, JUNG JOON LEE ${ }^{2}$, JUHEE SEO ${ }^{1}$ and JEONG-HYUNG LEE ${ }^{1}$ \\ ${ }^{1}$ Department of Biochemistry, College of Natural Sciences, Kangwon National University, Chuncheon 200-701; \\ ${ }^{2}$ Molecular Cancer Research Center, Korea Research Institute of Bioscience and Biotechnology, Daejeon 305-600, Korea
}

Received June 22, 2009; Accepted September 2, 2009

DOI: 10.3892/or_00000628

\begin{abstract}
Tumor necrosis factor-related apoptosis-inducing ligand (TRAIL) is a promising candidate for cancer therapeutics due to its ability to induce apoptosis selectively in cancer cells. However, sensitivity of cancer cells for induction of apoptosis by TRAIL varies considerably. Therefore, it is important to develop agents that overcome this resistance. We show, for the first time, that eupatolide, the sesquiterpene lactone isolated from the medicinal plant Inula britannica, sensitizes human breast cancer cells to TRAIL-induced apoptosis. Treatment with TRAIL in combination with subtoxic concentrations of eupatolide enhanced the TRAILinduced cytotoxicity in MCF-7, MDA-MB-231 and MDAMB-453 breast cancer cells, whereas each reagent alone slightly induced cell death. The combination induced sub- $\mathrm{G}_{1}$ phase DNA content and annexin V-staining in MCF-7 cells, which are major features of apoptosis. Apoptotic characteristics induced by the combined treatment were significantly inhibited by a pan-caspase inhibitor. The sensitization to TRAIL-induced apoptosis was accompanied by the activation of caspase- 8 and was concomitant with Bid and poly(ADP-ribose) polymerase (PARP) cleavage. Treatment of eupatolide alone significantly down-regulated the expression of cellular FLICE inhibitory protein (c-FLIP) in MCF-7 cells. Furthermore, enforced expression of c-FLIP significantly attenuated the apoptosis induced by this combination in $\mathrm{MCF}-7$ cells, suggesting a key role for c-FLIP down-regulation in these events. We also observed that euaptolide inhibited AKT phosphorylation in a dose- and time-dependent manner. Moreover, inhibition of Akt by LY294002, a specific PI3K inhibitor, down-regulated c-FLIP expression in MCF-7 cells. Taken together, these results indicate that eupatolide could augment TRAIL-induced apoptosis in human breast cancer cells by down-regulating
\end{abstract}

Correspondence to: Dr Jeong-Hyung Lee, Department of Biochemistry, College of Natural Sciences, Kangwon National University, Chuncheon 200-701, Korea

E-mail: jhlee36@kangwon.ac.kr

Key words: eupatolide, tumor necrosis factor-related apoptosisinducing ligand, apoptosis, cellular FLICE inhibitory protein, AKT
c-FLIP expression through the inhibition of AKT phosphorylation and be a valuable compound to overcome TRAIL resistance in breast cancer cells.

\section{Introduction}

Apoptosis is an essential process in human development, immunity and tissue homeostasis. The two primary apoptotic pathways are the death receptor and mitochondrial pathways $(1,2)$. Apoptotic signaling and execution through these two pathways is dependent on caspases, a group of cysteine proteases that degrade a critical set of cellular proteins near specific aspartic acid residues (3). In the death receptor pathway, the apoptosis-promoting members of the tumor necrosis factor superfamily, such as TRAIL and Fas ligand, engage their respective death receptors, DR4/DR5 or Fas, which homotypically bind to the adaptor protein FADD. FADD then recruits the initiating procaspases- 8 and -10 through homophilic death effector domain interactions to form the death inducing signaling complex (DISC) $(4,5)$. The close proximity of the initiator caspases in the DISC facilitates their dimerization and activation. The active caspase- 8 cleaves downstream effector caspases such as caspases-3, -6, and -7, as well as the pro-apoptotic protein Bid which initiates the mitochondrial apoptotic process (6). Cleaved Bid activates downstream pro-apoptotic proteins such as Bax and Bak which promote cytochrome c release from the mitochondria into the cytosol, thereby linking the two pathways (6). Cytochrome c associates with caspase-9, dATP and APAF-1 forming the apoptosome complex leading to the activation of caspase-9, which cleaves the downstream effector caspases $(7,8)$. Effector caspase activation promotes cellular disintegration by the cleavage of multiple cellular proteins such as PARP (9).

TRAIL belongs to the tumor necrosis factor (TNF) cytokine family and is a promising cancer drug because it induces apoptosis almost specifically in cancer cells $(10,11)$. TRAIL has been shown to induce apoptosis of breast cancer cell lines, although the sensitivity varies considerably, with the majority of cell lines being relatively resistant $(12,13)$. One issue of concern in TRAIL-based therapies is that a considerable number of tumor cells are resistant to TRAIL-induced apoptosis. Therefore, it is important to identify substances that potently restore TRAIL sensitivity in TRAIL resistance cells. TRAIL binds to the death-receptors DR4/DR5. Procaspase-8 zymogens are recruited by FADD to the DISC where they are 
cleaved through autoproteolysis (14). The caspase-8 cleavage can be inhibited by c-FLIP (15). There are two isoforms of c-FLIP: a short form $\left(c-F_{S} P_{S}\right)$ and a long form $\left(c-F_{L} P_{L}\right)$. Both c-FLIP $\mathrm{S}_{\mathrm{S}}$ and $\mathrm{c}-\mathrm{FLIP}_{\mathrm{L}}$ are recruited to the DISC where c-FLIP $_{L}$ is cleaved into a p43 intermediate form, which, together with c-FLIP , remains in the DISC where they inhibit caspase- 8 cleavage (16). c-FLIP is expressed in various cancers and its expression is associated with enhanced tumorigenicity and poor clinical outcome in many types of cancers because of chemotherapeutic drug and TRAIL resistance (17-19).

Inula britannica is the medicinal plant found in Eastern Asia, including China, Japan and Korea. Its extracts are reported to have anti-inflammatory, anti-diabetes and antitumor activities $(20,21)$. The sesquiterpene lactone eupatolide is an active ingredient of this plant, and shows several biological activities including inhibition of production of nitric oxide and induction of apoptosis $(22,23)$. As part of our continuing search to the natural products that sensitize TRAILinduced apoptosis, we have identified eupatolide. We showed for the first time that eupatolide sensitizes breast cancer cells to TRAIL-mediated apoptosis. Eupatolide-induced sensitization correlated with the activation of caspase- 8 , and cleavage of Bid, and cleavage of PARP. We also provide evidence that down-regulation of c-FLIP by eupatolide could play a critical role in the sensitization of TRAIL-induced apoptosis in human breast cancer cells.

\section{Materials and methods}

Cell culture and reagents. The MCF-7, MDA-MB-231 and MDA-MB-453 human breast cancer cell lines were obtained from the American Type Culture Collection (Rockville, MD, USA). Cells were maintained in Dulbecco's Modified Essential Medium supplemented with penicillin (100 units/ $\mathrm{ml})$-streptomycin $(100 \mu \mathrm{g} / \mathrm{ml})$ and $10 \%$ heat-inactivated fetal bovine serum in a humidified atmosphere containing $5 \% \mathrm{CO}_{2}$. TRAIL was purchased from R\&D systems (Minneapolis, MN, USA). Caspase-3 inhibitor II and LY294002 were purchased from Calbiochem (San Diego, CA, USA). Eupatolide was isolated from the aerial parts of I. britannica and confirmed its structure in comparison with a previous study (22) and its structure is shown in Fig. 1. The purity of eupatolide is $>98 \%$ in HPLC analysis.

Measurement of cell viability. For the determination of cytotoxicity, $1 \times 10^{4}$ cells per well were seeded in 96-well plates and allowed to grow for $48 \mathrm{~h}$. Eupatolide was added to the wells at the indicated concentrations either alone or in combination with $10,50,100 \mathrm{ng} / \mathrm{ml}$ of TRAIL for all cell lines and incubated for an additional $24 \mathrm{~h}$. Cell viability was determined by MTT [3-(4,5-dimethylthiazolyl-2)-2,5diphenyltetrazolium bromide]-based colorimetric assay. Data are expressed as the mean $\pm \mathrm{SD}$ of triplicate determinations from at least 3 independent experiments.

Western blot analysis. Proteins were extracted from cells in ice-cold lysis buffer (50 mM Tris- $\mathrm{HCl}, \mathrm{pH} 7.5,1 \%$ Nonidet P-40, 1 mM EDTA, $1 \mathrm{mM}$ phenylmethyl sulfonyl fluoride, $1 \mu \mathrm{g} / \mathrm{ml}$ leupeptin, $1 \mathrm{mM}$ sodium vanadate, $150 \mathrm{mM} \mathrm{NaCl}$ ).
Fifty $\mu \mathrm{g}$ of protein per lane was separated by sodium dodecyl sulfate (SDS)-polyacrylamide gel electrophoresis (PAGE) and followed by transferring to a polyvinylidene difluoride membrane (Millipore, Bedford, MA, USA). The membrane was blocked with 5\% skim milk and then incubated with the corresponding antibody. Antibodies for caspase-8, PARP, Bid, c-FLIP, Bax, Bcl-2, c-IAP1, cIAP2, p-Akt (Ser473) and Akt were purchased from Cell Signaling Technology (Beverly, MA, USA). Antibody for $\alpha$-tubulin was from Sigma (St. Louis, MO, USA). After binding of an appropriate secondary antibody coupled to horseradish peroxidase, proteins were visualized by enhanced chemiluminescence according to the instructions of the manufacturer (Amersham Pharmacia Biotec, Buckinghamshire, UK).

Reverse transcription-polymerase chain reaction (RT-PCR). MCF-7 cells were treated with eupatolide alone or in combination with $100 \mathrm{ng} / \mathrm{ml}$ of TRAIL for the indicated times. The cells were harvested and total RNA was isolated using RNeasy mini kits (Qiagen, Santa Clarita, CA, USA) according to the manufacturer's instructions. Two $\mu \mathrm{g}$ of total RNA was used to synthesis 1st stranded cDNA using RT-PCR kit (Invitrogen, Carlsbad, CA, USA). For amplification of the c-FLIP $_{\mathrm{L}}$ and c-FLIP , the following primers were used: cFLIP $_{\mathrm{L}}$, 5'-CAGAGATTGGTGAGGATTTGGATAAA TCTG-3' (sense), 5'-CCTAGGGGCTTGCTCTTCATCTT GTA-3' (antisense), c-FLIP, , 5'-CAGAGATTGGTGAGGA TTTGGATAAATCTG-3' (sense), 5'-GGAACAATTTCCA AGAATTTTCAGATCAGG-3' (antisense). The cDNA for GAPDH was also amplified as a control in a similar way using the following primers: 5'-ACCACAGTCCATGC CATCAC-3' (sense), 5'-TCCACCACCCTGTTGCTGTA-3' (antisense). For PCR amplification, the following conditions were used: $94^{\circ} \mathrm{C}$ for $2 \mathrm{~min}$ for 1 cycle and then $94^{\circ} \mathrm{C}$ for $1 \mathrm{~min}$, $57^{\circ} \mathrm{C}$ for $30 \mathrm{sec}$ and $72^{\circ} \mathrm{C}$ for $1 \mathrm{~min}$ for 30 cycles. The amplified PCR products were separated with $1.5 \%$ agarose gel and then stained with EtBr.

Apoptosis detection. The extent of apoptosis was evaluated with hypodiploid content of DNA and annexin V-staining. MCF-7 cells were treated with $10 \mu \mathrm{M}$ eupatolide in the absence or presence of $100 \mathrm{ng} / \mathrm{ml}$ TRAIL for $24 \mathrm{~h}$. For the determination of hypodipoid content of DNA, the cells were washed twice with cold PBS and then centrifuged. Briefly, the pellet was fixed in $75 \%$ (vol/vol) ethanol for $1 \mathrm{~h}$ at $4^{\circ} \mathrm{C}$. The cells were washed once with PBS and resuspended in cold propidium iodide solution $(50 \mu \mathrm{g} / \mathrm{ml})$ containing RNase A $(0.1 \mathrm{mg} / \mathrm{ml})$ in PBS (pH 7.4) for $30 \mathrm{~min}$ in the dark. Flow cytometry analyses were performed using FACSCalibur (Becton-Dickinson, San Jose, CA, USA). Forward light scatter characteristics were used to exclude the cell debris from the analysis. The sub- $\mathrm{G}_{1}$ population was calculated to estimate the apoptotic cell population. The CellQuest software was used to analyze the data (Becton-Dickinson). Annexin V-staining was performed using annexin V-FITC apoptosis detection kit (BD Biosciences, CA, USA) following the instructions of the manufacturer. Briefly, after incubation, cells were harvested, washed with PBS ( $\mathrm{pH} 7.4)$, centrifuged and stained with annexin V-FITC and $2 \mu \mathrm{g} / \mathrm{ml}$ propidium iodide in binding buffer (10 mM Hepes, pH 7.4, $140 \mathrm{mM} \mathrm{NaCl}, 2.5 \mathrm{mM} \mathrm{CaCl}_{2}$ ) 
A)<smiles>C=C1C(=O)O[C@H](/C=C\CCC=C2C=CCC2)[C@@H]1O</smiles>

B)

MCF-7

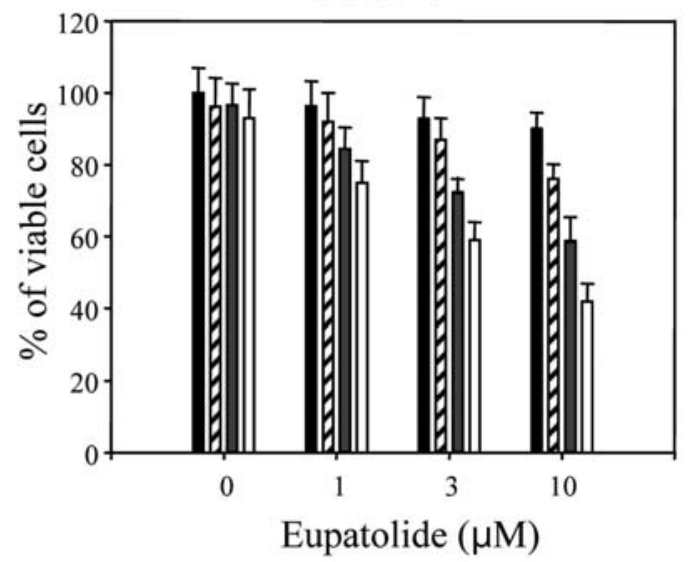

MDA-MB-453

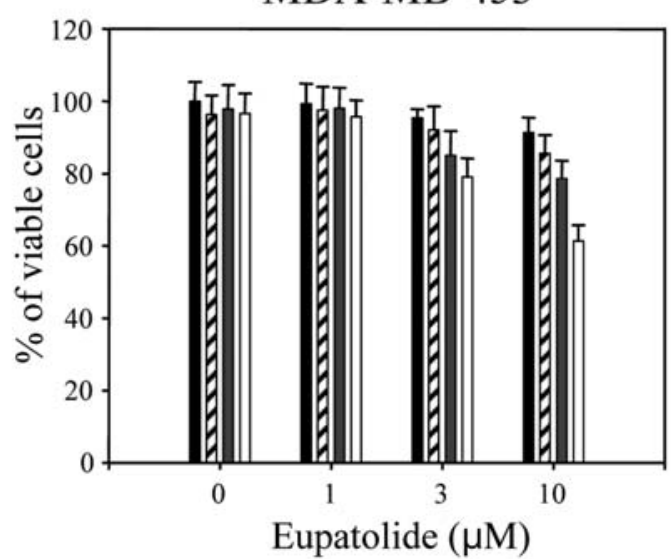

MDA-MB-231

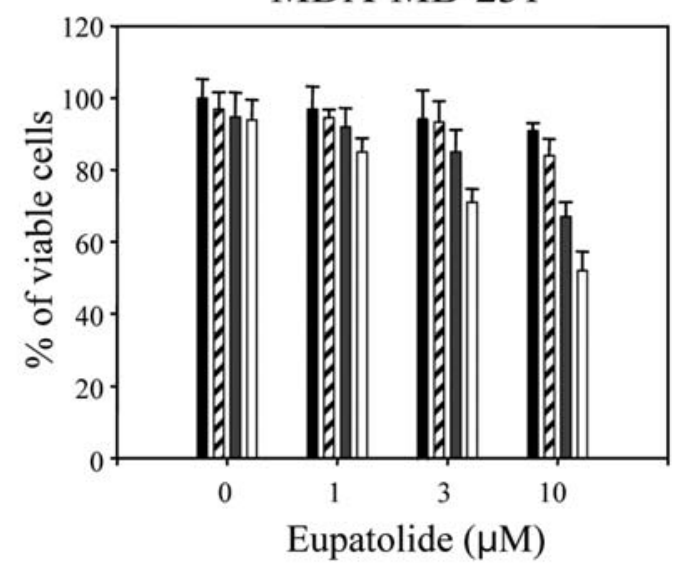

TRAIL $0 \mathrm{ng} / \mathrm{ml}$

WZ TRAIL $10 \mathrm{ng} / \mathrm{ml}$

$\square$ TRAIL $50 \mathrm{ng} / \mathrm{ml}$ TRAIL $100 \mathrm{ng} / \mathrm{ml}$

Figure 1. Induction of cell death in human breast cancer cell lines by eupatolide and TRAIL. (A) Chemical structure of eupatolide. (B) Effect of eupatolide on TRAIL-induced cell death. Cells were seeded in triplicates into 96-well plates and cultured with eupatolide (0-10 $\mu \mathrm{M})$ alone, or in combination with TRAIL $(0-100 \mathrm{ng} / \mathrm{ml})$ for $24 \mathrm{~h}$. Cell viability was determined by MTT assay. Data are presented as the mean \pm SD from two independent experiments, and are expressed as a percentage of the number of control cells.

for $15 \mathrm{~min}$ at $37^{\circ} \mathrm{C}$ in the dark. The samples were analyzed by flow cytometry using a FACScan flow cytometer. The CellQuest software was used to analyze the data (BectonDickinson).

Detection of DR-4 and DR-5 expression on cell surface. MCF-7 cells treated with the eupatolide or vehicle alone for $16 \mathrm{~h}$ were harvested, washed with PBS and suspended in PBS containing $1 \%$ bovine serum albumin. Then, $3 \mu \mathrm{l}$ of phycoerythrin-conjugated anti-DR5, anti-DR4, or mouse IgG control antibody (eBiosciences, CA, USA) were added to cells and incubated on ice for $30 \mathrm{~min}$. After washing with PBS, DR5 and DR4 expression on cell surface was analyzed in FITC-positive cell population by flow cytometry.

Statistical analysis. Data represent mean \pm SD of triplicate data. Data were analyzed using a Student's t-test and differences were considered significant from controls at $\mathrm{P}<0.05$. 


\section{Results}

Eupatolide cooperates with TRAIL to induce death of breast cancer cells. The cytotoxic activity of TRAIL was tested with MTT assays in three human breast cancer cell lines: MCF-7, MDA-MB-453 and MDA-MB-231 (Fig. 1). Treatment of 10 to $100 \mathrm{ng} / \mathrm{ml}$ of TRAIL induced limited cell death $(<15 \%)$ over $24 \mathrm{~h}$, suggesting that these breast cancer cell lines are resistance to the cytotoxic effect of TRAIL. Next, we investigated the cytotoxic effect of eupatolide alone or in combination with TRAIL in these cells. Eupatolide alone did not show significant cytotoxic effect up to $10 \mu \mathrm{M}$. However, cell viability was significantly reduced by the combined treatment both when holding the concentration of TRAIL fixed and varying the concentration of eupatolide and when holding the concentration of euaptolide fixed and varying the concentration of TARIL. Treatment of MCF-7 cells with 100 $\mathrm{ng} / \mathrm{ml}$ of TRAIL or $10 \mu \mathrm{M}$ of eupatolide reduced cell viability to $12 \pm 2$ and $5 \pm 0.3 \%$, respectively, of control level at $24 \mathrm{~h}$. However, combined treatment of $100 \mathrm{ng} / \mathrm{ml}$ of TRAIL and $10 \mu \mathrm{M}$ of eupatolide resulted in the reduction of cell viability to $43 \pm 5 \%$ of control level (Fig. 1A). Similar results were observed in MDA-MB-231 and MDA-MB-453 cells (Fig. $1 B)$. These results show that combined treatment of eupatolide and TRAIL effectively induces cell death in these breast cancer cell lines.

Eupatolide sensitizes MCF-7 cells to TRAIL-induced apoptosis. We then investigated whether apoptotic cell death is induced by a combination of eupatolide and TRAIL in MCF-7 cells. In order to quantify apoptosis induction, we measured the amount of hypodiploid cell populations using flow cytometric analysis. Cotreatment of MCF-7 cells with $10 \mu \mathrm{M}$ eupatolide and $100 \mathrm{ng} / \mathrm{ml}$ TRAIL for $24 \mathrm{~h}$ significantly increased the accumulation of sub- $\mathrm{G}_{1}$ phase cells, whereas treatment with eupatolide or TRAIL alone did not (Fig. 2A). Pretreatment with a pan-caspase inhibitor (caspase inhibitor II) significantly blocked the accumulation of sub- $\mathrm{G}_{1}$ phase cell populations induced by eupatolide plus TRAIL (Fig. 2A). Annexin V/PI staining assays also revealed that combined treatment of eupatolide plus TRAIL significantly induced apoptosis and a pan-caspase inhibitor significantly blocked the induction of apoptosis (Fig. 2B). As the TNF superfamily members reportedly share similar protein structures and death receptormediated apoptotic signaling pathways (24), we next tested whether eupatolide could also sensitize TNF- $\alpha$-mediated apoptosis. Similar with our TRAIL results, eupatolide also sensitizes MCF-7 cells to TNF- $\alpha$-induced apoptosis and a pan-caspase inhibitor suppressed this effect (Fig. 2C). Collectively, these results suggest that eupatolide stimulates TRAIL-induced, caspase-dependent apoptosis, possibly targeting the common component(s) of the death receptormediated apoptotic pathway.

Combination with eupatolide and TRAIL results in the caspase- 8 activation and PARP cleavage, but does not alter the expression of DR4/DR5. To delineate the mechanisms by which eupatolide promotes TRAIL-induced apoptosis, MCF-7 cells were treated with $100 \mathrm{ng} / \mathrm{ml}$ of TRAIL alone or in combination with $10 \mu \mathrm{M}$ of eupatolide for $12 \mathrm{~h}$. Cell lysates
A)

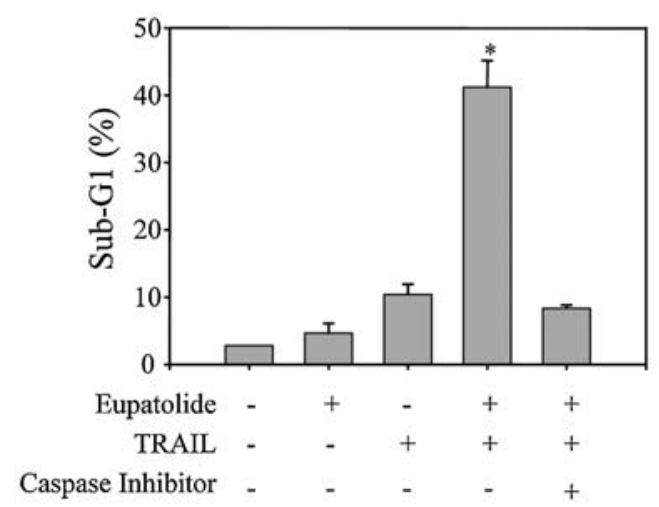

B)

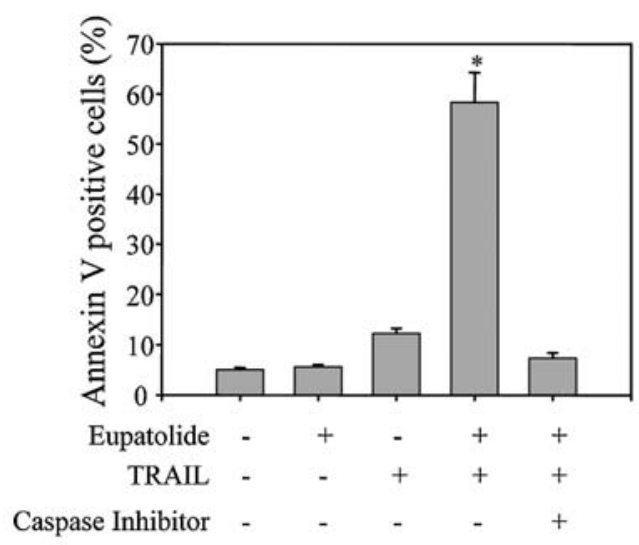

C)

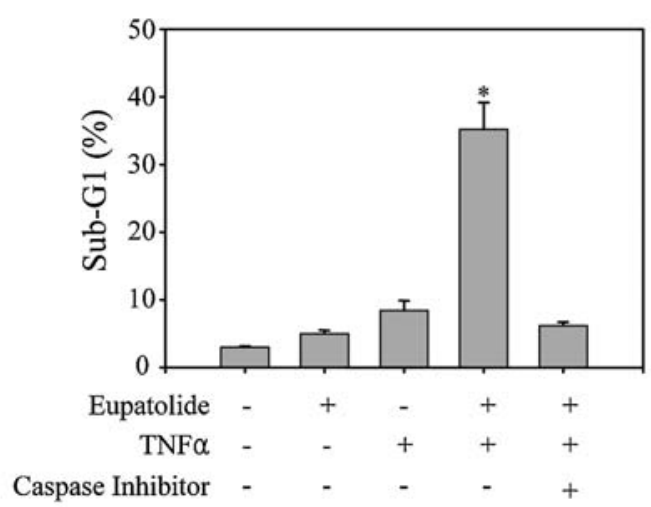

Figure 2. Effect of eupatolide on TRAIL- and TNF- $\alpha$-induced apoptosis in MCF-7 cells. (A and B) MCF-7 cells were treated with $10 \mu \mathrm{M}$ eupatolide alone, or in combination with $100 \mathrm{ng} / \mathrm{ml}$ TRAIL for $24 \mathrm{~h}$. To examine the effect of the inhibition of casapses, MCF-7 cells were pretreated with $30 \mu \mathrm{M}$ caspase inhibitor II for $30 \mathrm{~min}$ prior to the addition of $10 \mu \mathrm{M}$ eupatolide plus $100 \mathrm{ng} / \mathrm{ml}$ TRAIL. Apoptosis levels were determined as the percentage of cells with hypodiploid content of DNA in the pre- $\mathrm{G}_{0} / \mathrm{G}_{1}$ region (A) and annexin $\mathrm{V}$-staining (B) using flow cytometry. (C) Effect of eupatolide on TNF- $\alpha$ induced apoptosis. MCF-7 cells were treated as described (A and B), but TNF- $\alpha(20 \mathrm{ng} / \mathrm{ml})$ was treated instead of TRAIL. Apoptosis levels were determined as the percentage of cells with hypodiploid content of DNA in the pre- $\mathrm{G}_{0} / \mathrm{G}_{1}$ region using flow cytometry. Data are presented as the mean $\pm \mathrm{SD}$ from three independent experiments. Asterisks indicate a significant difference compared the control.

were then analyzed by immunoblotting for proteolytic processing of procaspase- 8 , the caspase- 8 substrate $\mathrm{Bid}$, and caspase-3 substrate PARP (Fig. 3A). Treatment with $10 \mu \mathrm{M}$ of eupatolide or $100 \mathrm{ng} / \mathrm{ml}$ of TRAIL alone was barely 
A)

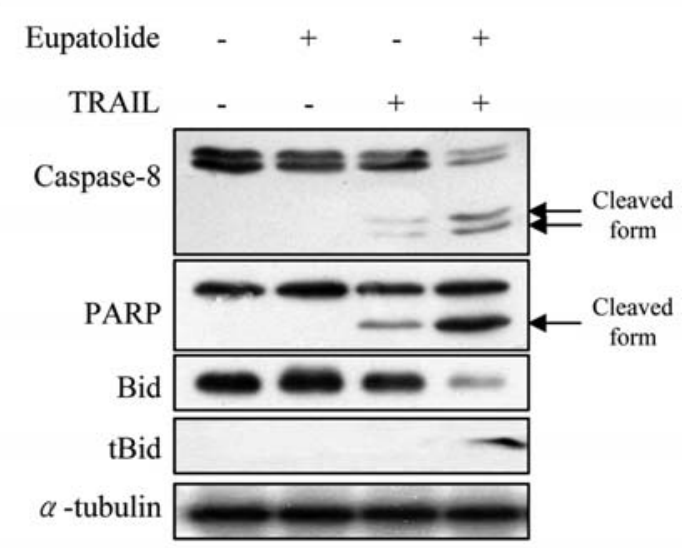

B)
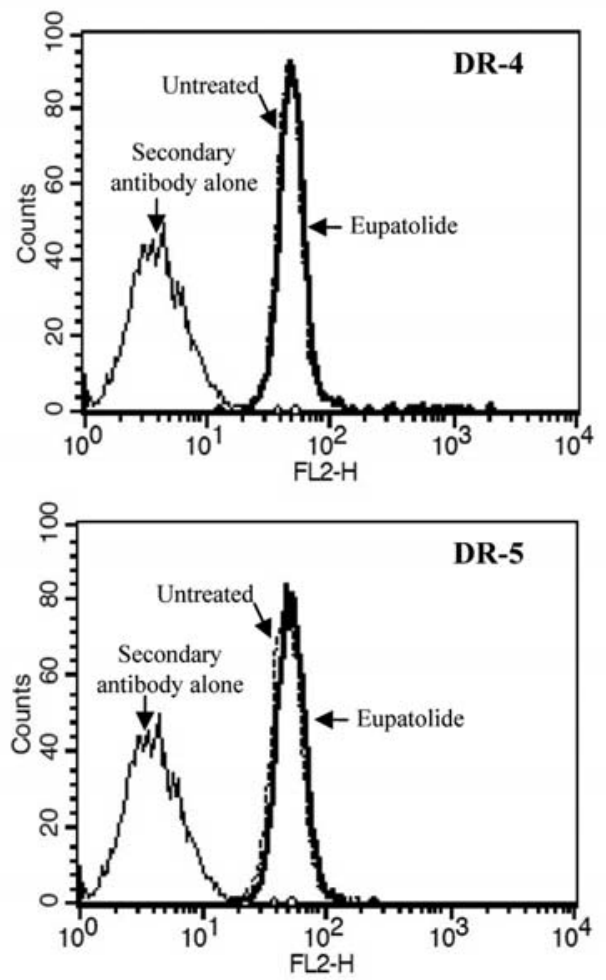

Figure 3. Effect of eupatolide on TRAIL-induced proteolytic cleavage of caspase-8, Bid, and PARP, and cell surface expression of TRAIL receptors. (A) MCF-7 cells were treated with $10 \mu \mathrm{M}$ eupatolide alone, or in combination with $100 \mathrm{ng} / \mathrm{ml}$ TRAIL for $24 \mathrm{~h}$. The cell lysates were analyzed by Western blotting with specific antibodies (anti-caspase-8, anti-PARP and anti-Bid). The data are representative of three independent experiments. (B) Effect of eupatolide on the surface expression levels of DR4 and DR5. MCF-7 cells were incubated with or without $10 \mu \mathrm{M}$ eupatolide for $16 \mathrm{~h}$ and then the surface expression of DR5 and DR4 proteins was analyzed by flow cytometry. X axis, fluorescence intensity; Y axis, relative number of cells.

detectable the proteolytic processing of procaspase-8, Bid and PARP. However, combined treatment with eupatolide and TRAIL resulted in robust procaspase- 8 processing, Bid cleavage and PARP proteolysis. Because TRAIL is known to trigger apoptotic signals via two types of death receptors, DR4 and DR5 $(25,26)$, we next investigated whether the modulation of DR4 and/or DR5 expression levels by eupatolide might be involved in its sensitizing effect on TRAIL-induced apoptosis
(Fig. 3B). FACS analysis showed that eupatolide did not modulate the surface expression levels of DR4 and DR5 in MCF-7 cells.

TRAIL sensitization by eupatolide is mediated by downregulation of c-FLIP protein expression, but not $m R N A$ expression. We next examined the effect of eupatolide on the expression of apoptosis-regulating proteins in MCF-7 cells (Fig. 4A). The expression levels of Bcl-2, IAP-1, IAP-2 and Bax were not changed by eupatolide alone or cotreatment with eupatolide and TRAIL. However, eupatolide alone significantly down-regulated the expression of both c-FLIP $\mathrm{L}_{\mathrm{L}}$ and $\mathrm{c}-\mathrm{FLIP}_{\mathrm{S}}$. In addition, the expression levels of $\mathrm{c}-\mathrm{FLIP}_{\mathrm{L}}$ and $\mathrm{c}^{-F_{L I P}} \mathrm{~S}_{\mathrm{S}}$ expression were markedly decreased by cotreatment with eupatolide and TRAIL. To examine whether eupatolideinduced down-regulation of c-FLIP is controlled at the transcriptional level, we performed RT-PCR analysis of cFLIP $_{\mathrm{L}}$ and c-FLIP $\mathrm{S}$ (Fig. 4B). We found that the mRNA expression levels of c-FLIP $_{\mathrm{L}}$ and $\mathrm{c}-\mathrm{FLIP}_{\mathrm{S}}$ were not changed by eupatolide alone or cotreatment with eupatolide and TRAIL, suggesting that down-regulation of c-FLIP ${ }_{L}$ and cFLIP $_{S}$ expression could be regulated at the post-transcriptional level. To further confirm the inhibitory effect of eupatolide on the c-FLIP ${ }_{\mathrm{L}}$ and c-FLIP $\mathrm{S}$ expression, MCF-7 cells were treated with $10 \mu \mathrm{M}$ of eupatolide for 6,12 and $24 \mathrm{~h}$ and then the expression levels of c-FLIP $\mathrm{L}_{\mathrm{L}}$ and $\mathrm{c}-\mathrm{FLIP}_{\mathrm{S}}$ were determined (Fig. 4C and D). We found that treatment of $10 \mu \mathrm{M}$ of eupatolide resulted in the gradual decrease in the protein expression levels of c-FLIP ${ }_{\mathrm{L}}$ and c-FLIP by $24 \mathrm{~h}$ (Fig. 4C). However, the mRNA expression levels did not change by this treatment (Fig. 4D).

To clarify the functional role of c-FLIP in sensitization of TRAIL-induced apoptosis by eupatolide, we examined the effect of c-FLIP overexpression on the apoptosis induced by cotreatment with eupatolide and TRAIL (Fig. 4E). Overexpression of c-FLIP significantly inhibited the sensitizing effect of eupatolide on the TRAIL-induced apoptosis in MCF-7 cells, suggesting that eupatolide-induced downregulation of c-FLIP plays a critical role in enhancement of TRAIL-induced apoptosis in MCF-7 cells.

Down-regulation of c-FLIP by eupatolide is mediated via inhibition of AKT phosphorylation. It has been reported that $\mathrm{PI} 3 \mathrm{~K} / \mathrm{Akt}$ pathway is involved in the regulation of c-FLIP expression, which is a key mediator of TRAIL resistance in several human cancer cells (27-29). Therefore, we investigated whether eupatolide might inhibit the activity of Akt. MCF-7 cells were treated with $10 \mu \mathrm{M}$ of eupatolide for the indicated times and then the expression level of phospho-Akt was determined by immnunoblotting using phospho-specific S473 Akt antibody (Fig. 5A). We found that treatment of $10 \mu \mathrm{M}$ of eupatolide resulted in the gradual decrease in the phosphorylation levels of Akt by $6 \mathrm{~h}$. Furthermore, eupatolide inhibited the phosphorylation of Akt in a dose-dependent manner (Fig. 5B). In order to address the possible link between Akt and c-FLIP expression, we next examined whether inhibition of Akt down-regulates the expression of c-FLIP in MCF-7 cells (Fig. 5C). Preincubation of eupatolide or the PI3K inhibitor LY294002 significantly suppressed both c-FLIP 
A)

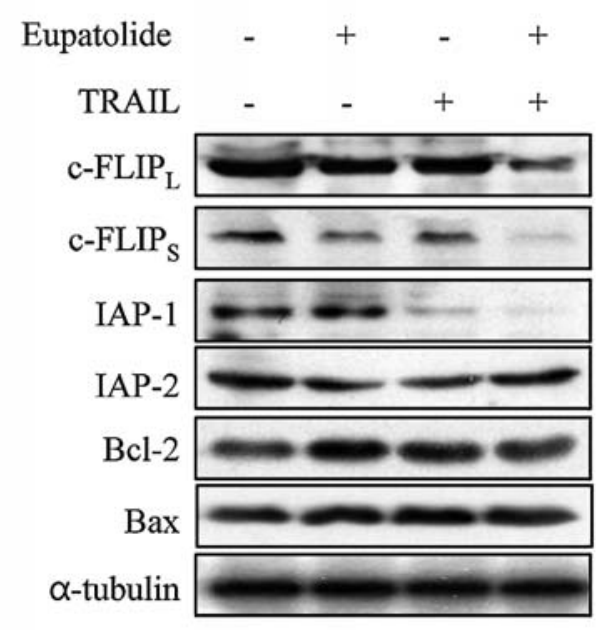

C)

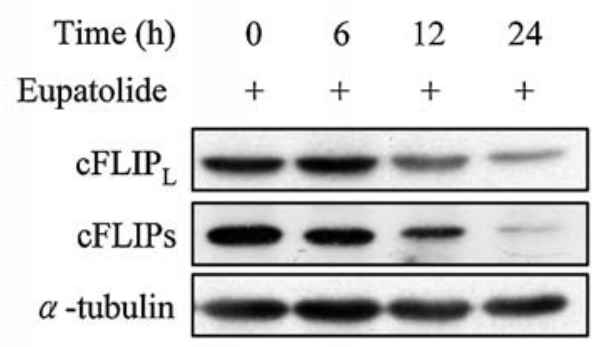

B)

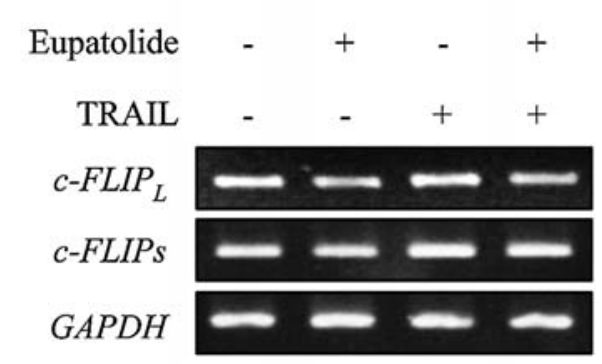

D)

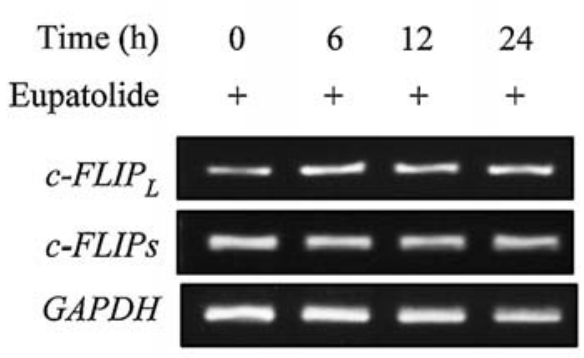

E)

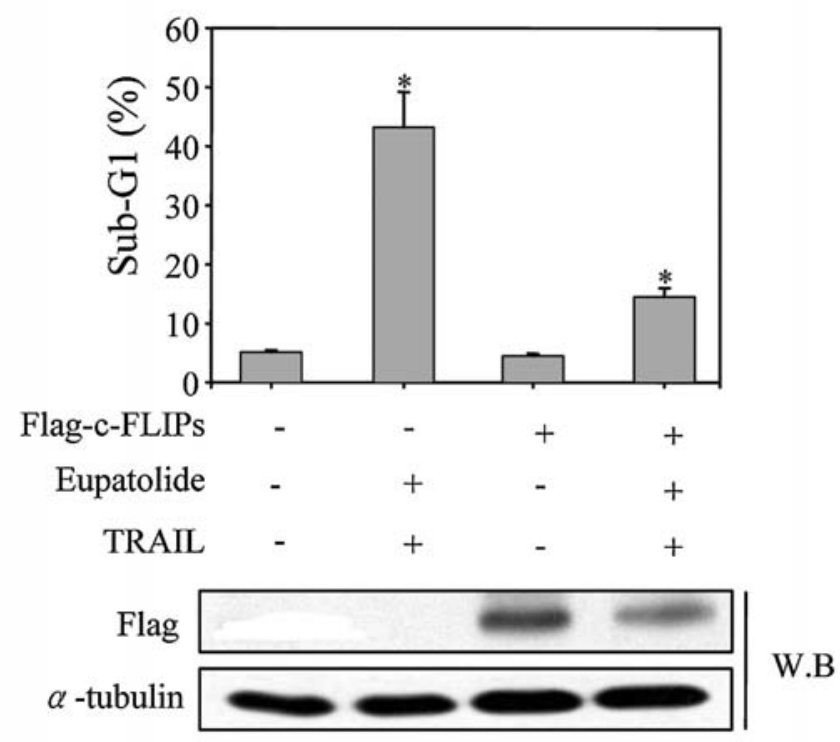

Figure 4. Effect of eupatolide on the expression level of c-FLIP. (A) MCF-7 cells were treated with $10 \mu \mathrm{M}$ eupatolide alone, or in combination with $100 \mathrm{ng} / \mathrm{ml}$ TRAIL for $24 \mathrm{~h}$. The cell lystaes were analyzed by Western blotting with specific antibodies (anti-c-FLIP, anti-cIAP1, anti-cIAP2, anti-Bax and anti-Bcl2). The data are representative of three independent experiments. (B) RT-PCR analysis of c-FLIP mRNA expression. MCF-7 cells were treated as described (A). Total RNA was isolated, and the expression levels of c-FLIP $\mathrm{L}_{\mathrm{L}}$, c-FLIP $\mathrm{S}_{\mathrm{S}}$ and GAPDH were determined by RT-PCR. (C and D) Effect of eupatolide on the expression of protein (C) and mRNA (D) of c-FLIP. MCF-7 cells were incubated with eupatolide (10 $\mu \mathrm{M})$ for the indicated times. The expression levels of FLIP $_{L}$ and FLIP ${ }_{S}$ were analyzed by Western blotting (C) or RT-PCR (D). (E) Effect of c-FLIP overexpression on the eupatolide-mediated sensitization of TRAIL-induced apoptosis. MCF-7 cells were transiently transfected with a Flag-tagged c-FLIP $\mathrm{S}_{\mathrm{S}}$ expression vector. After $48 \mathrm{~h}$, the cells were treated with $10 \mu \mathrm{M}$ eupatolide and $100 \mathrm{ng} / \mathrm{ml}$ TRAIL and further incubated for the additional $24 \mathrm{~h}$. Apoptosis levels were determined as the percentage of cells with hypodiploid content of DNA in the pre $-\mathrm{G}_{0} / \mathrm{G}_{1}$ region using flow cytometry. Data are presented as the mean \pm SD from three independent experiments. Asterisks indicate a significant difference compared to the control. 
A)

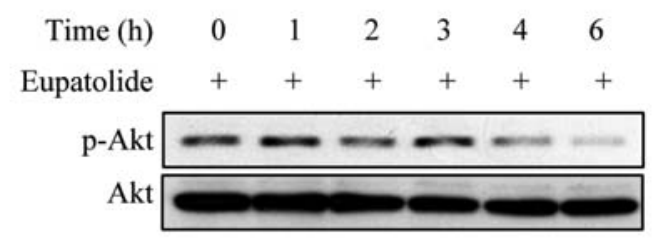

B)

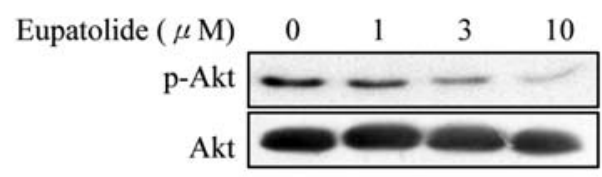

C)

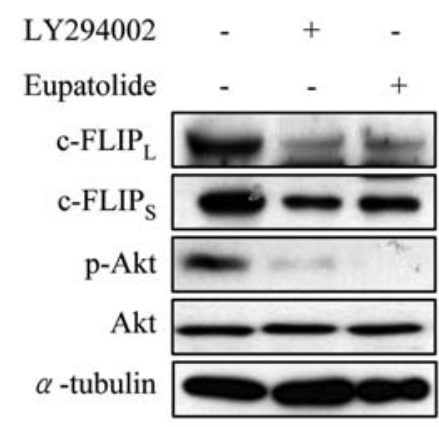

Figure 5. Effect of eupatolide on the activation of Akt and expression of c-FLIP in MCF-7 cells. (A) MCF-7 cells were treated with $10 \mu \mathrm{M}$ eupatolide for the indicated times. The level of phospho-Akt was determined by Western blot analysis. (B) MCF-7 cells were treated with the indicated concentrations of eupatolide for $6 \mathrm{~h}$. Cell lysates were prepared, and the level of phospho-Akt was determined by Western blot analysis. (C) MCF-7 cells were treated with $10 \mu \mathrm{M}$ eupatolide or $10 \mu \mathrm{M}$ LY294002 for $12 \mathrm{~h}$. Cell lysates were prepared, and the levels of c-FLIP ${ }_{\mathrm{L}}, \mathrm{c}-\mathrm{FLIP}_{\mathrm{S}}$, Akt and p-Akt were determined by Western blot analysis.

expression and Akt phosphorylation, suggesting that inhibition of Akt phosphorylation by eupatolide could be involved in the eupatolide-induced down-regulation of c-FLIP.

\section{Discussion}

Members of the TNF receptor superfamily, including TNF receptor, Fas and TRAIL receptor, share similar conserved structures (24). Although TNF- $\alpha$ and FasL can trigger apoptosis in some solid tumors, their clinical usage has been limited by the risk of lethal systemic inflammation and hepatotoxicity, respectively $(30,31)$. TRAIL selectively induces apoptosis in cancer cells in vitro and in vivo with little or no toxicity toward normal cells $(10,11)$. Therefore, TRAIL is one of the most promising new candidates for anti-tumor therapeutics. However, previous studies have shown that considerable numbers of cancer cells are resistant to the apoptotic effects of TRAIL $(12,13,32)$. Thus, it is of importance to develop agents that sensitize cancer cells to TRAILinduced apoptosis to improve therapeutic impact of TRAIL.

In this study, we investigated the ability of eupatolide, a naturally occurring member of sequiterpene lactone, to enhance TRAIL-induced apoptosis in human breast cancer cells. We showed for the first time that subtoxic doses of eupatolide sensitize human breast cancer cells to TRAILinduced apoptosis by down-regulating c-FLIP expression. Cellular sensitivity to TRAIL can be affected by the expression levels of the cell membrane TRAIL receptors, caspase-8, or c-FLIP (32). Moreover, it has been reported that downregulation of c-FLIP is sufficient to confer sensitivity against TRAIL- and FasL-mediated apoptosis $(33,34)$. We found that eupatolide causes a significant decrease in the levels of proteins for c-FLIP ${ }_{\mathrm{L}}$ and c-FLIP , but the expression of cell membrane TRAIL receptors, DR4 and DR5 was not changed in MCF-7 breast cancer cells. We also showed that overexpression of c-FLIP significantly inhibited the apoptosis induced by the combination of eupatolide and TRAIL in MCF-7 cells, confirming that down-regulation of c-FLIP by eupatolide is functionally significant in sensitizing the effect of eupatolide on TRAIL-mediated apoptosis. Several studies have demonstrated that certain compounds, such as synthetic triterpenoids, honokiol, and flavopiridol, can induce downregulation of c-FLIP and subsequent sensitization of TRAILinduced apoptosis in cancer cells (35-37). Similar with these compounds, eupatolide was able to sensitize cancer cells to TRAIL-induced apoptosis by down-regulating c-FLIP. It is noteworthy that eupatolide sensitized MCF-7 cells to TNF- $\alpha$ induced apoptosis. As a structural homologue of caspase-8, c-FLIP binds FADD, competing with caspase- 8 for recruitment to DISC. Therefore, c-FLIP suppression by eupatolide could be involved in mediating the sensitization of cancer cells to TNF- $\alpha$ or TRAIL-induced apoptosis. Regarding TRAIL receptors, certain compounds, such as celecoxib, kaemferol and sulforaphane, sensitize cancer cells to TRAIL-induced apoptosis by up-regulation of DR5 (38-40). Eupatolide did not modulate the expression of DR4 and DR5, suggesting that TRAIL receptors could not be of particular importance in eupatolide facilitated TRAIL-induced apoptosis.

In several types of cancers, increased c-FLIP expression is correlated with resistance to TRAIL-, Fas-, or TNF-induced apoptosis $(17-19,41,42)$. Post-translational modification and degradation of c-FLIP as well as increased mRNA levels have been suggested to be involved in increasing c-FLIP expression (43). It has been reported that the activation of PI3K/Akt pathway inhibits the death-receptor mediated apoptotic pathway through the up-regulation of c-FLIP expression (27-29). We showed that eupatolide inhibited Akt phoshorylation in a dose- and time-dependent manner. Furthermore, inhibition of Akt by LY294002 resulted in the down-regulation of c-FLIP, indicating that eupatolide may down-regulate cFLIP protein levels through inhibition of Akt. In agreement with our findings, a recent study showed that the alkylphospholipid perifosine, an Akt inhibitor, induces apoptosis of human lung cancer cells by down-regulating c-FLIP (44). Accordingly, inhibition of Akt by eupatolide could contribute to the down-regulation of c-FLIP. However, the detailed mechanism by which eupatolide regulates the expression of c-FLIP remains to be elucidated.

Taken together, we have found that eupatolide, a sesquiterpene lactone from I. britannica, enhanced TRAILmediated apoptosis in human breast cancer cells, which appeared to be mediated through a mechanism involving inhibition of c-FLIP expression and Akt activation. Eupatolide 
may a valuable compound for sensitizing TRAIL-induced apoptosis in breast cancer cells.

\section{Acknowledgements}

This work was supported by a grant from the Korea Healthcare technology R\&D Project, Ministry for Health and Welfare, Republic of Korea (No. A080405).

\section{References}

1. Debatin KM and Krammer PH: Death receptors in chemotherapy and cancer. Oncogene 23: 2950-2966, 2004.

2. Cereghetti GM and Scorrano L: The many shapes of mitochondrial death. Oncogene 25: 4717-4724, 2006.

3. Green D and Kroemer G: The central executioners of apoptosis: caspases or mitochondria? Trends Cell Biol 8: 276-271, 1998

4. Ashkenazi A and Dixit VM: Death receptors: signaling and modulation. Science 281: 1305-1308, 1998.

5. Sprick MR, Weigand MA, Rieser E, Rauch CT, Juo P, Blenis J, Krammer PH and Walczak H: FADD/MORT1 and caspase-8 are recruited to TRAIL receptors 1 and 2 and are essential for apoptosis mediated by TRAIL receptor 2. Immunity 12: 599-609, 2000 .

6. Gogvadze V and Orrenius S: Mitochondrial regulation of apoptotic cell death. Chem Biol Interact 163: 4-14, 2006.

7. Liu X, Kim CN, Yang J, Jemmerson R and Wang X: Induction of apoptotic program in cell-free extracts: requirement for dATP and cytochrome c. Cell 86: 147-157, 1996.

8. Jiang $X$ and Wang X: Cytochrome c-mediated apoptosis. Annu Rev Biochem 73: 87-106, 2004.

9. Strasser A, O'Connor L and Dixit VM: Apoptosis signaling. Annu Rev Biochem 69: 217-245, 2000.

10. Walczak H, Miller RE, Ariail K, Gliniak B, Griffith TS, Kubin M, Chin W, Jones J, Woodward A, Le T, Smith C, Smolak P, Goodwin RG, Rauch CT, Schuh JC and Lynch DH: Tumoricidal activity of tumor necrosis factor-related apoptosis-inducing ligand in vivo. Nat Med 5: 157-163, 1999.

11. Ashkenazi A, Pai RC, Fong S, Leung S, Lawrence DA, Marsters SA, Blackie C, Chang L, McMurtrey AE, Hebert A, DeForge L, Koumenis IL, Lewis D, Harris L, Bussiere J, Koeppen H, Shahrokh Z and Schwall RH: Safety and antitumor activity of recombinant soluble Apo2 ligand. J Clin Invest 104: 155-162, 1999.

12. Singh TR, Shankar S, Chen X, Asim M and Srivastava RK: Synergistic interactions of chemotherapeutic drugs and tumor necrosis factor-related apoptosis-inducing ligand/Apo-2 ligand on apoptosis and on regression of breast carcinoma in vivo. Cancer Res 63: 5390-5400, 2003.

13. Keane MM, Ettenberg SA, Nau MM, Russell EK and Lipkowitz S: Chemotherapy augments TRAIL-induced apoptosis in breast cell lines. Cancer Res 59: 734-741, 1999.

14. Scaffidi C, Medema JP, Krammer PH and Peter ME: FLICE is predominantly expressed as two functionally active isoforms, caspase-8/a and caspase-8/b. J Biol Chem 272: 26953-26958, 1997.

15. Irmler M, Thome M, Hahne M, Schneider P, Hofmann K, Steiner V, Bodmer JL, Schroter M, Burns K, Mattmann C, Rimoldi D, French LE and Tschopp J: Inhibition of death receptor signals by cellular FLIP. Nature 388: 190-195, 1997.

16. Krueger A, Baumann S, Krammer PH and Kirchhoff S: FLICEinhibitory proteins: regulators of death receptor-mediated apoptosis. Mol Cell Biol 21: 8247-8254, 2001.

17. Gao S, Wang H, Lee P, Melamed J, Li CX, Zhang F, Wu H, Zhou L and Wang Z: Androgen receptor and prostate apoptosis response factor-4 target the c-FLIP gene to determine survival and apoptosis in the prostate gland. J Mol Endocrinol 36: 463-483, 2006.

18. Valnet-Rabier MB, Challier B, Thiebault S, Angonin R, Margueritte G, Mougin C, Kantelip B, Deconinck E, Cahn JY and Fest T: c-Flip protein expression in Burkitt's lymphomas is associated with a poor clinical outcome. Br J Haematol 128: 767-773, 2005

19. Steele LP, Georgopoulos NT, Southgate J, Selby PJ and Trejdosiewicz LK: Differential susceptibility to TRAIL of normal versus malignant human urothelial cells. Cell Death Differ 13: 1564-1576, 2006.
20. Kobayashi T, Song QH, Hong T, Kitamura H and Cyong JC: Preventative effects of the flowers of Inula britannica on autoimmune diabetes in $\mathrm{C} 57 \mathrm{BL} / \mathrm{KsJ}$ mice induced by multiple low doses of streptozotocin. Phytother Res 16: 377-382, 2002.

21. Rafi MM, Bai NS, Chi-Tang-Ho, Rosen RT, White E, Perez D and Dipaola RS: A sesquiterpenelactone from Inula britannica induces anti-tumor effects dependent on $\mathrm{Bcl}-2$ phosphorylation. Anticancer Res 25: 313-318, 2005.

22. Jin HZ, Lee D, Lee JH, Lee K, Hong YS, Choung DH, Kim YH and Lee JJ: New sesquiterpene dimers from Inula britannica inhibit NF- $\kappa \mathrm{B}$ activation and $\mathrm{NO}$ and $\mathrm{TNF}-\alpha$ production in LPSstimulated RAW264.7 cells. Planta Med 72: 40-45, 2006.

23. Bai N, Lai CS, He K, Zhou Z, Zhang L, Quan Z, Zhu N, Zheng QY, Pan MH and Ho CT: Sesquiterpene lactones from Inula britannica and their cytotoxic and apoptotic effects on human cancer cell lines. J Nat Prod 69: 531-535, 2006.

24. Locksley RM, Killeen N and Lenardo MJ: The TNF and TNF receptor superfamilies: integrating mammalian biology. Cell 104: 487-501, 2001.

25. Pan G, O'Rourke K, Chinnaiyan AM, Gentz R, Ebner R, Ni J and Dixit VM: The receptor for the cytotoxic ligand TRAIL. Science 276: 111-113, 1997.

26. Sheridan JP, Marsters SA, Pitti RM, Gurney A, Skubatch M, Baldwin D, Ramakrishnan L, Gray CL, Baker K, Wood WI, Goddard AD, Godowski P and Ashkenazi A: Control of TRAILinduced apoptosis by a family of signaling and decoy receptors. Science 277: 818-821, 1997.

27. Kang YC, Kim KM, Lee KS, Namkoong S, Lee SJ, Han JA, Jeoung D, Ha KS, Kwon YG and Kim YM: Serum bioactive lysophospholipids prevent TRAIL-induced apoptosis via PI3K/ Akt-dependent cFLIP expression and Bad phosphorylation. Cell Death Differ 11: 1287-1298, 2004.

28. Nam SY, Jung GA, Hur GC, Chung HY, Kim WH, Seol DW and Lee BL: Upregulation of FLIP(S) by Akt, a possible inhibition mechanism of TRAIL-induced apoptosis in human gastric cancers. Cancer Sci 94: 1066-1073, 2003

29. Panka DJ, Mano T, Suhara T, Walsh K and Mier JW: Phosphatidylinositol 3-kinase/Akt activity regulates c-FLIP expression in tumor cells. J Biol Chem 276: 6893-6896, 2001.

30. Fiers W: Tumor necrosis factor. Characterization at the molecular, cellular and in vivo level. FEBS Lett 285: 199-212, 1991.

31. Ogasawara J, Watanabe-Fukunaga R, Adachi M, Matsuzawa A, Kasugai T, Kitamura Y, Itoh N, Suda T and Nagata S: Lethal effect of the anti-Fas antibody in mice. Nature 364: 806-809, 1993.

32. Van Geelen CM, de Vries EG and de Jong S: Lessons from TRAIL-resistance mechanisms in colorectal cancer cells: paving the road to patient-tailored therapy. Drug Resist Updat 7: 345-358, 2004.

33. Geserick P, Drewniok C, Hupe M, Haas TL, Diessenbacher P, Sprick MR, Schön MP, Henkler F, Gollnick H, Walczak H and Leverkus M: Suppression of cFLIP is sufficient to sensitize human melanoma cells to TRAIL- and CD95L-mediated apoptosis. Oncogene 27: 3211-3220, 2008.

34. Ricci MS, Kim SH, Ogi K, Plastaras JP, Ling J, Wang W, Jin Z, Liu YY, Dicker DT, Chiao PJ, Flaherty KT, Smith CD and El-Deiry WS: Reduction of TRAIL-induced Mcl-1 and cIAP2 by c-Myc or sorafenib sensitizes resistant human cancer cells to TRAIL-induced death. Cancer Cell 12: 66-80, 2007.

35. Hyer ML, Croxton R, Krajewska M, Krajewski S, Kress CL, Lu M, Suh N, Sporn MB, Cryns VL, Zapata JM and Reed JC: Synthetic triterpenoids cooperate with tumor necrosis factorrelated apoptosis-inducing ligand to induce apoptosis of breast cancer cells. Cancer Res 65: 4799-4808, 2005.

36. Palacios C, Yerbes R and Lopez-Rivas A: Flavopiridol induces cellular FLICE-inhibitory protein degradation by the proteasome and promotes TRAIL-induced early signaling and apoptosis in breast tumor cells. Cancer Res 66: 8858-8869, 2006.

37. Raja SM, Chen S, Yue P, Acker TM, Lefkove B, Arbiser JL, Khuri FR and Sun SY: The natural product honokiol preferentially inhibits cellular FLICE-inhibitory protein and augments death receptor-induced apoptosis. Mol Cancer Ther 7: 2212-2223, 2008.

38. Liu X, Yue P, Zhou Z, Khuri FR and Sun SY: Death receptor regulation and celecoxib-induced apoptosis in human lung cancer cells. J Natl Cancer Inst 96: 1769-1780, 2004.

39. Yoshida T, Konishi M, Horinaka M, Yasuda T, Goda AE, Taniguchi H, Yano K, Wakada M and Sakai T: Kaempferol sensitizes colon cancer cells to TRAIL-induced apoptosis. Biochem Biophys Res Commun 375: 129-133, 2008. 
40. Kim H, Kim EH, Eom YW, Kim WH, Kwon TK, Lee SJ and Choi KS: Sulforaphane sensitizes tumor necrosis factor-related apoptosis-inducing ligand (TRAIL)-resistant hepatoma cells to TRAIL-induced apoptosis through reactive oxygen speciesmediated up-regulation of DR5. Cancer Res 66: 1740-1750, 2006.

41. Wilson TR, McLaughlin KM, McEwan M, Sakai H, Rogers KM, Redmond KM, Johnston PG and Longley DB: c-FLIP: a key regulator of colorectal cancer cell death. Cancer Res 67: 5754-5762, 2007.

42. Liu X, Yue P, Schonthal AH, Khuri FR and Sun SY: Cellular FLICE-inhibitory protein down-regulation contributes to celecoxib-induced apoptosis in human lung cancer cells. Cancer Res 66: 11115-11119, 2006.
43. Dutton A, Young LS and Murray PG: The role of cellular FLICE inhibitory protein (c-FLIP) in the pathogenesis and treatment of cancer. Expert Opin Ther Targets 10: 27-35, 2006.

44. Elrod HA, Lin YD, Yue P, Wang X, Lonial S, Khuri FR and Sun SY: The alkylphospholipid perifosine induces apoptosis of human lung cancer cells requiring inhibition of Akt and activation of the extrinsic apoptotic pathway. Mol Cancer Ther 6: 2029-2038, 2007. 